\title{
Oxidative strand scission of DNA
}

\author{
Teruo Matsuura, Isao Saito, Hiroshi Sugiyama, Takashi Morii and Hiroshi Kawabata \\ Department of Synthetic Chemistry, Faculty of Engineering, \\ Kyoto University, Yoshida, Kyoto 606, Japan
}

\begin{abstract}
Various types of oxygen-dependent anticancer drugs such as bleomycin and neocarzinostatin are known to cleave DNA strands oxidatively. We have made various organic chemical approaches in order to elucidate their action mechanisms, particularly mechanisms of oxidation reactions occurring at the deoxyribosyl moiety of DNA. Our approaches include the reactions of model hydroperoxy and hydroxy intermediates and the quantitative analysis of the cleavage reactions using synthetic self-complimentary oligonucleotides.
\end{abstract}

\section{INTRODUCTION}

Various chemical reagents and certain anticancer drugs such as the Fenton reagent and oxygendependent anticancer drugs, are known to cleave DNA strands by the attack of a free radical or a reactive oxygen species generated from these systems. The successful application of the photochemical reaction of thymidine with lysine to the selective cleavage of DNA strands at thymine sites (ref. 1), prompted us to investigate the oxidative scission of DNA by certain systems generating a free radical or a reactive oxygen species. Our particular attention has been drawn to the action of oxygen-dependent anticancer drugs such as bleomycin and neocarzinostatin, because of their unique chemical structures and their ability to cleave DNA in a site-specific manner.

The action mechanisms for such anticancer drugs may generally involve the following three steps: (i) recognition of a particularbase or base sequence on a DNA double strand, (ii) activation of the substrate or molecular oxygen under the reaction conditions, and (iii) oxidation reactions leading to DNA strand scission. This report deals mainly with the third step.

\section{MODEL 4'-HYDROPEROXY, 4'-HYDROXY AND I'-HYDROXY INTERMEDIATES}

In case of bleomycin, the third step has been reported to involve the formation of $4^{\prime}$-hydroperoxy and 4'-hydroxy deoxyribosyl intermediates which lead to the strand scission of DNA giving a base-propenal and a free base, respectively, as shown in Scheme 1 (ref. 2).

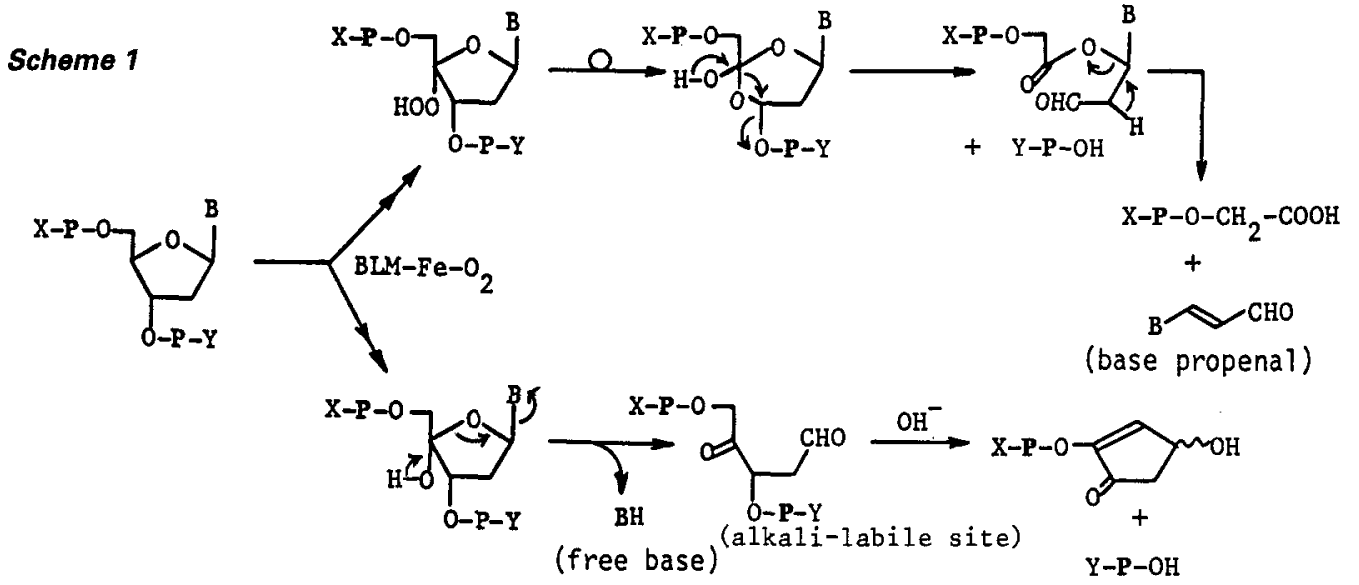

Since the chemistry of such $4^{\prime}$-hydroperoxy and $4^{\prime}$-hydroxy nucleosides was totally unknown, we studied model reactions for the mechanisms of Scheme 1. A model 4'-hydroperoxide 1 synthesized was submitted to spontaneous decomposition in a phosphate buffer at $\mathrm{pH} 6 . \overline{0}$ to give thymine-propenal, acetic acid and benzoic acid in good yield. When hydroperoxide 1 was reduced with dimethyl sulfide in methanol, free thymine and an alkali-labile site añalog 
were obtained in nearly quantitative yield (ref, 3). These model reactions support the DNA scission mechanisms of Scheme 1.

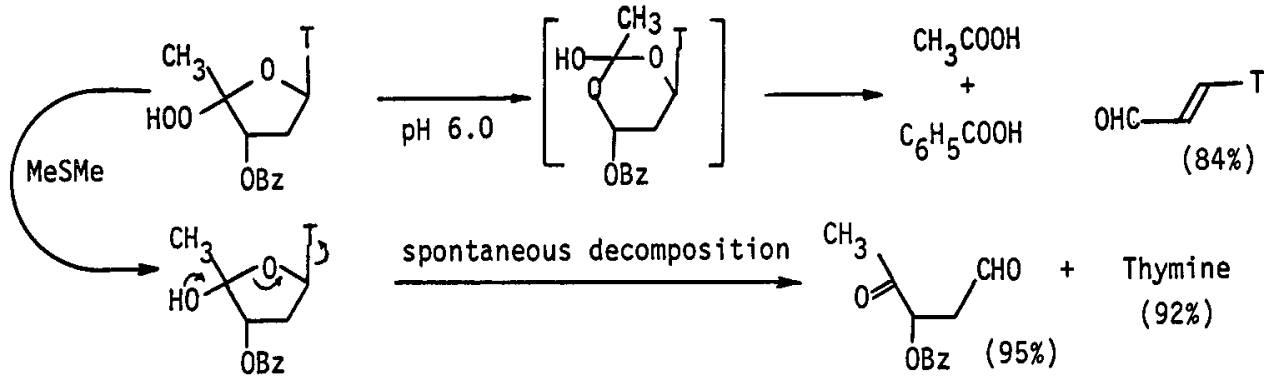

1'-Bydroxylation of the sugar moisty of DNA has been proposed for the strand scission of DNA with the hydroxyl radical (together with hydroxylation at other positions) and phenanthroline-copper (I)-hydrogen peroxide (ref. 4). In these cases, a free base and a butenolide may be formed as Scheme 2. A model reaction for $1^{\prime}$-hydroxylation was carried out using an intramolecular oxygen atom transfer reaction of compound $\underline{2}$ which gave thymine and a lactone $\underline{3}$ in comparative yield. The site-selective monooxygenation reactions using this type of perester has been developed in our laboratory (ref. 5).

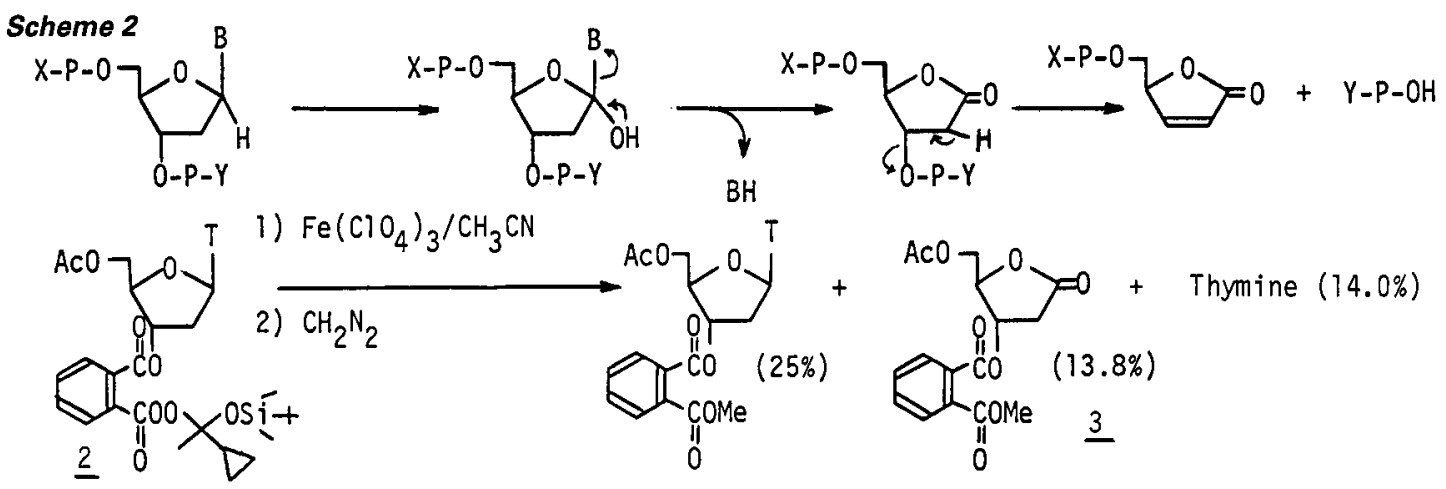

\section{PHOTOCHEMICAL CLEAVAGE OF DNA WITH BLEOMYCIN-Co(III)-OOH}

When $\mathrm{Fe}$ (II) is replaced by Co(II), bleomycin does not undergo DNA cleavage reaction even in the presence of oxygen and a reducing agent. However, DNA cleavage reaction occurs when the bleomycin-Co(II)-oxygen system is irradiated with UV light. The mechnism of this photochemical activation has been proposed by Mears et al. (ref. 6). They isolated two bleomycinCo(III) complexes, a hydroperoxy and an aquo complexes, from the dark reaction of bleomycinCo(II) complex with oxygen. These Co (III) complexes are capable of DNA cleavage under UV irradiation.

$$
\mathrm{BLM}-\mathrm{Co}(\mathrm{II})-\mathrm{O}_{2} \longrightarrow \mathrm{BLM}-\mathrm{Co}(\mathrm{III})-\mathrm{OOH} \text { (green) }+\mathrm{BLM}-\mathrm{Co}(\mathrm{III})-\mathrm{H}_{2} \mathrm{O} \text { (brown) }
$$

We found that the site-specificity of this photochemical DNA cleavage was same (G-C and G-T) as that of the bleomycin-Fe(II)-mediated DNA cleavage. Next, we analyzed quantitatively the cleavage products by HPLC using an oligonucleotide, $5^{\prime}$-CGCG-3', in the photochemical clavage reaction. This type of analytical method has been developed by Hecht and his collaborators (ref. 7). Scheme 3 shows the products which are expected to form via 4'-hydroperoxy and $4^{\prime}$-hydroxy intermediates from the reaction of $5^{\prime}$-CGCG-3'. Among these products, only cytosine (C) and compound 4 were determined by HPLC (Figure 1), indicating that the photochemical cleavage reaction of $5^{\prime}-\mathrm{CGCG}^{\prime} 3^{\prime}$ with bleomycin-Co(III)-OOH occurred via the $4^{\prime}$-hydroxy intermediate. The same cleavage reaction was observed with bleomycin-Co(III) $-\mathrm{E}_{2} \mathrm{O}$ complex at a much slower rate.

There may be a number of mechanisms which interprete the formation of $4^{\prime}$-hydroxy intermediate in the photochemical cleavage of DNA with BLM-Co(III)-OOH complex. A possible mechanism is shown below involving the homolytic cleavage of the $0-0$ bond of the Co(III) complex.

$$
\begin{aligned}
& \mathrm{BLM}-\mathrm{Co}(\mathrm{III})-\mathrm{OOH}+\mathrm{h \nu} \rightarrow \mathrm{BLM}-\mathrm{CO}(\mathrm{III})-\mathrm{O}+\quad+. \mathrm{OH} \\
& \mathrm{BLM}-\mathrm{Co}(\mathrm{III})-\mathrm{O}+\mathrm{RH} \longrightarrow \mathrm{BLM}-\mathrm{Co}(\mathrm{III})-\mathrm{OH}+\mathrm{R} \text {. } \\
& \text { (brown complex) } \\
& \text { R. }+. \mathrm{OH} \longrightarrow \mathrm{R}-\mathrm{OH} \text { (4'-hydroxy intermediate) }
\end{aligned}
$$


Scheme 3

(PEM: peplomycin)

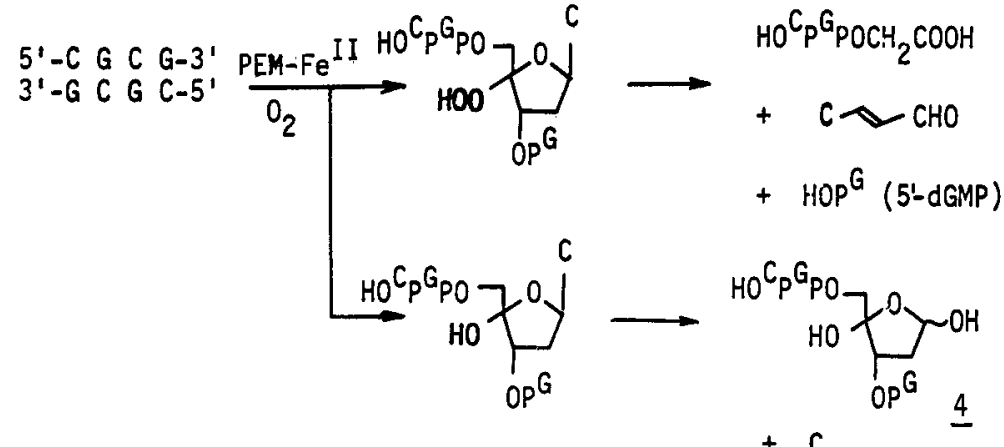

$+C$

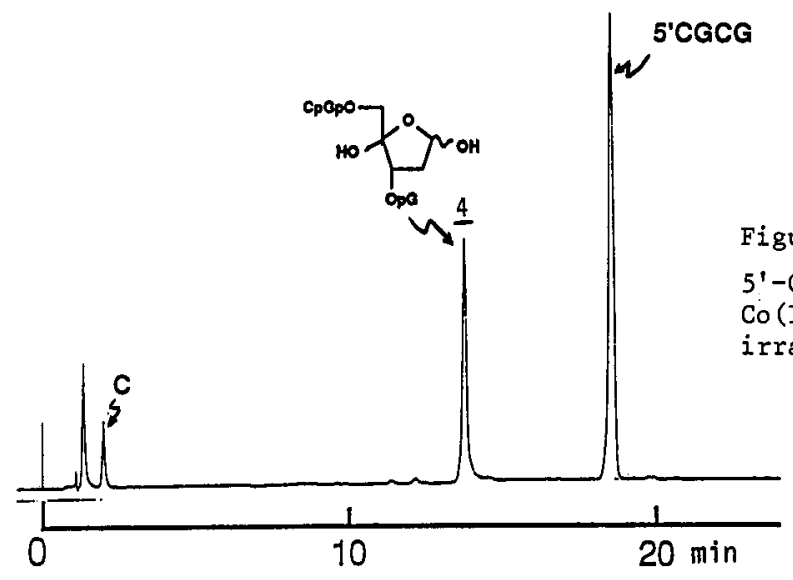

Figure 1. HPLC analysis of products. 5'-CGCG-3' was treated with peplomycin$\mathrm{Co}$ (III) $-\mathrm{OOH}$ at $0^{\circ} \mathrm{C}$ for $2 \mathrm{hr}$. under $366 \mathrm{~nm}$ irradiation.

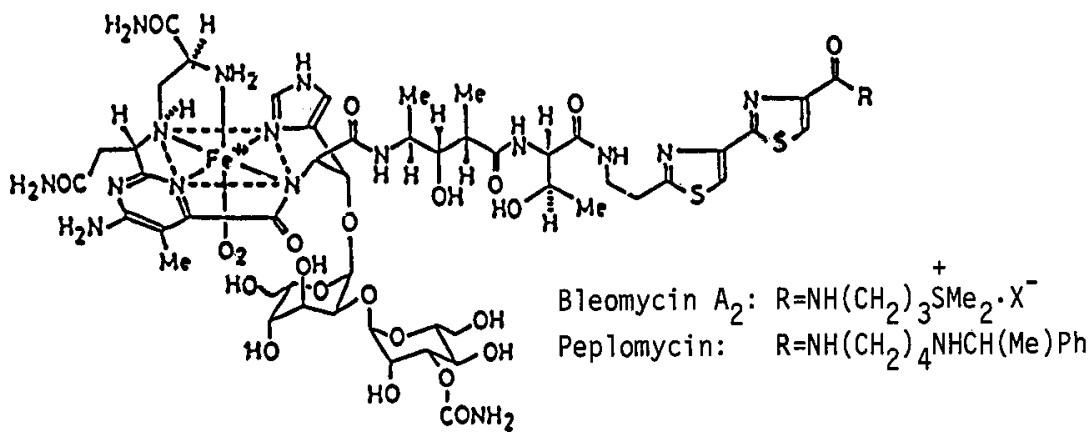

\section{DNA STRAND SCISSION WITH NEOCARZINOSTATIN}

Neocarzinostatin is a complex molecule between an apoprotein and a chromophore and is known to cleave DNA specifically at thymine sites in the presence of a thiol and molecular oxygen. Goldberg et al. have suggested that 5'-oxidation predominanty occurs at the deoxyribose moiety (ref. 7). Recently Meyers has proposed a mechanism involving the formation of a biradical intermediate which may abstract hydrogen from DNA (ref. 8).

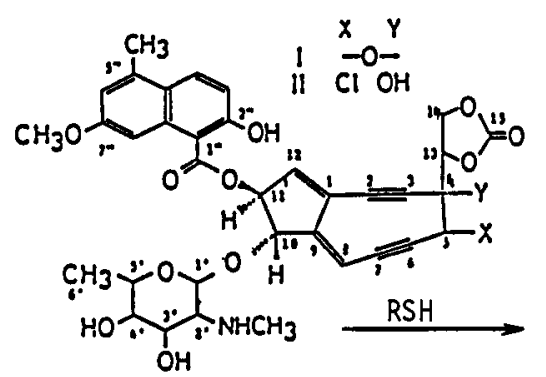

Neocarzinostatin chromophore

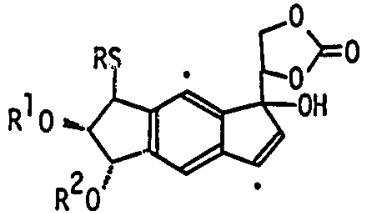<smiles>CC(C)[Mg]</smiles> 
We confirmed the thymine specificity for the neocarzinostatin-mediated scission of calf thymus DNA. Thus, in the oxidation of calf thymus DNA with neocarzinostatin-4-hydroxythiophenol-oxygen, thymine formed was $69 \%$ of total free bases obtained from the reaction mixture.

We next examined the reaction of neocarzinostatin with a synthetic oligonucleotide, $5^{\prime}-$ GCATGC-3'. If 5'-hydroperoxy and 5'-hydroxy intermediates are formed by selective 5'-oxidation, these two intermediates would eventually give four products shown in Scheme 4. Although compound 5 was not detected on HPLC possibly because of its instability, all other products were obtained together with the starting nucleotide in a good material balance (Figure 2). The material balance indicates that these cleavage products are formed most probably via the $5^{\prime}$-oxidation as shown in Scheme 4.

\section{Scheme 4}
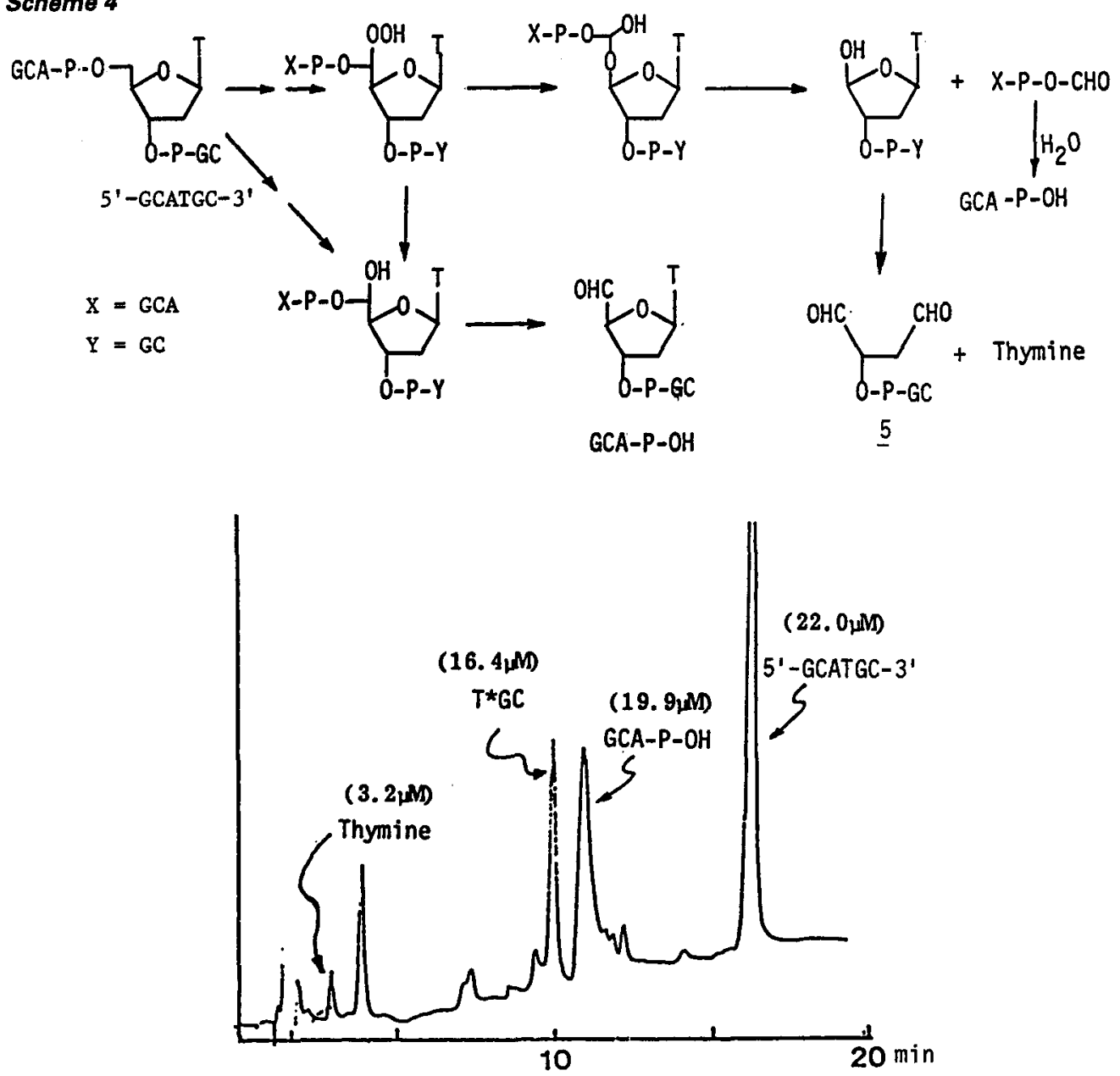

Figure 2. HPLC analysis of products.

$5^{\prime}$-GCATGC (42 uM) was treated with neocarzinostatin (250 $\left.\mu \mathrm{M}\right)$ and 4-hydroxythiophenol $(3.5 \mathrm{mM})$ in $50 \mathrm{mM}$ Tris-HCl buffer at $\mathrm{pH} 7.0$ and $0^{\circ} \mathrm{C}$ for $7 \mathrm{~h}$.

\section{REFERENCES}

1. I. Saito and T. Matsuura, Accounts Chem. Res., 18, 134-140. (1985).

2. For a leading review, see: J. Stubbe and J. W. Kozarich, Chem. Rev., 87, 1107-1136 (1987).

3. I. Saito, T. Morii and T. Matsuura, J. Org. Chem., 52, 1008-1012 (1987)

4. T. E. Goyne and D. S. Sigman, J. Am. Chem. Soc., 109, 2846-2848 (1987).

5. I. Saito, T. Mano, R. Nagata, N. Uematsu and T. Matsuura, in "The Role of Oxygen in Chemistry and Biochemistry", W. Ando and Y. Moro-oka, Eds., Elsevier Sci. Pub1. Amsterdam, p. 73-78 (1988).

6. C.-H. Chang, J. L. Dallas and C. F. Mears, Biochem. Biophys. Res. Commun., 110, 959 (1983).

7. L. S. Kappen and I. H. Goldberg, Biochemistry, 22, 4872-4878 (1983).

8. A. G. Meyers, Tetrahedron Letters, 28, 4493-4496 (1987). 